
J. Hoffmann
J. Linseisen
J. Riedl
G. Wolfram

\footnotetext{
Dr. J. Hoffmann J. Linseisen J. Riedl · G. Wolfram

Institute of Nutritional Sciences

Technical University of Munich

Alte Akademie 16

D-85350 Freising-Weihenstephan

Tel.: +8161-713763

Fax: $+8161-713931$
}

\section{Dietary fiber reduces the antioxidative effect of a carotenoid and $\alpha$-tocopherol mixture on LDL oxidation ex vivo in humans}

\author{
Summary Background: Antioxidant \\ concentrations in low density \\ lipoproteins (LDL) are an important \\ determinant for their susceptability \\ to oxidation and can be modulated \\ by dietary intake. Aim of the study: \\ In the present study, the influence \\ of dietary fiber on the antioxidant \\ enrichment and the oxidation \\ resistance of LDL after antioxidant \\ $22 \%$, and $18 \%$, respectively. \\ Conclusions: These results indicate \\ that dietary fiber supplementation \\ decreases the antioxidative effect of \\ a supplement consisting of \\ carotenoids and $\alpha$-tocopherol in \\ LDL, an effect that is likely to be \\ mediated by a reduced \\ bioavailability of these antioxidants \\ in the gut.
} supplementation is investigated. Method: An antioxidant supplement consisting of $\beta$-carotene, lycopene, lutein, canthaxanthin and $\alpha$-tocopherol was given to six young women together with a standard meal. Using a cross-over study design, each subject received the standard meal without additional dietary fiber and enriched with pectin, guar, or cellulose in a random order. To determine the resistance of LDL against copper ion-induced oxidation, the formation of conjugated dienes was measured. Results: Eight, 10, and 24 hours after antioxidant supplementation the isolated LDL revealed significantly $(\mathrm{p}<0.05)$ increased antioxidant concentrations; addition of pectin, guar, or cellulose to the meal depressed this increase. Concomitantly, the observed increase in the resistance of LDL against oxidation (measured as lag phase) was lower with dietary fiber supplementation than that found without. On average, pectin, guar, and cellulose reduced the increase of the lag phase (measured without addition of dietary fiber) by $38 \%$,

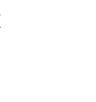




\section{Introduction}

Many of the putative biologic effects and health benefits of carotenoids and $\alpha$-tocopherol are thought to occur through protection against oxidative damage [1]. Oxidation of LDL, the major cholesterol-carrying lipoprotein in human plasma, is implicated with the development of cardiovascular disease. Oxidized LDL has been shown to accelerate several steps in atherogenesis, including endothelial damage, monocyte-macrophage recruitment, increased uptake of LDL by foam cells, and induction of growth factors [2]. LDL is protected against oxidation by its antioxidants, i.e., tocopherols and carotenoids. It has been demonstrated that oxidation of human LDL can only occur when it is largely depleted of its antioxidants [3]. The first disappearing antioxidants are $\alpha$ - and $\gamma$-tocopherol, thereafter lycopene, cryptoxanthin, lutein, and $\beta$-carotene as the last one [4]. Accordingly, most research on LDL oxidation has concentrated on $\alpha$-tocopherol. In vitro and ex vivo experiments have shown that $\alpha$-tocopherol increases the resistance of LDL against oxidation [5-8]. Carotenoids are also known as effective antioxidants in LDL, but they showed a clear protective effect on LDL oxidation only after in vitro supplementation [4, 9-11), whereas ex vivo the results are controversial $[12-15]$. There are some indications that counteraction with carotenoids or other coantioxidants makes $\alpha$ tocopherol as efficient for LDL protection [16-18].

The amount of exogenous antioxidants in LDL depends on our nutritional habits. By the consumption of fruits and vegetables, a great variety of natural antioxidants can be provided to the organism. However, the efficency of absorption of most antioxidants is still under discussion. Recent literature reports described interactions between carotenoids at the absorption site [19-22]. Furthermore, less is known about interaction of antioxidants with other food components, such as dietary fiber. It is well known that dietary fiber can reduce the bioavailability of macronutrients, especially fat, and of some minerals and trace elements in the human diet. Since it was demonstrated in humans that pectin strongly decreased the bioavailability of $\beta$-carotene [23], dietary fiber is suspected to also affect the absorption of other carotenoids and probably of $\alpha$-tocopherol.

The present study aimed to test the effect of different kinds of dietary fiber on the enrichment of LDL with concomitantly supplemented carotenoids and $\alpha$-tocopherol. Moreover, possible consequences for the oxidation resistance of LDL should be highlighted.

\section{Methods}

\section{Subjects}

Six healthy, nonsmoking young women (age 26-29 years) participated in the study. They showed body weight (body mass index $19.00-21.87 \mathrm{~kg} / \mathrm{m}^{2}$ ) and plasma lipids within physiological ranges, and did not use oral contraceptives. The participants gave informed consent to the study. The procedures followed were in accord with the Helsinki Declaration of 1975 as revised in 1983.

\section{Study design}

Each subject took part on four individual test days. The subjects were instructed by a dietitian and a list of foods to be avoided, to follow a diet low in carotenoids and $\alpha$-tocopherol every three days before the test days. On the test day, the fasted subjects received a test meal together with an antioxidant supplement for breakfast. The test meal contained either no additional dietary fiber or was supplemented with pectin or guar or cellulose. The different types of dietary fiber were given in random order, considering that each subject should receive a different type within a test day (cross over). The test days were separated by a wash-out period of at least two weeks. Blood sampling was performed before test meal intake $(0 \mathrm{~h})$ as well as 8,10 , and 24 hours thereafter.

Test meal, antioxidant and fiber supplement

The test meal (rice pudding) provided $20 \%$ of the daily energy requirement (REE x 1.5) [24]. It contained $27 \%$ of the energy from fat, 59\% from carbohydrates and $14 \%$ from protein. The remaining energy requirement $(80 \%)$ was supplied with a fiber-free liquid diet in six portions every two hours after the test meal (Nutricomp F, B. Braun Melsungen AG, Melsungen/Germany: 24\% of energy as fat, $59 \%$ as carbohydrates and $17 \%$ as protein; $0.75 \mathrm{mg} \alpha$-tocopherol $/ 100 \mathrm{ml} ; 5.0 \mathrm{mg}$ vitamin $\mathrm{C} / 100 \mathrm{ml}$; no carotenoids; no selenium).

The antioxidant supplement consisted of $\beta$-carotene (0.4 mg kg/body weight; Hoffmann-La Roche, GrenzachWyhlen/Germany), lycopene $(0.7 \mathrm{mg} \mathrm{kg} /$ body weight; LycoRed Natural Products Industries Ltd., Beer-Sheva/ Israel), lutein $(0.4 \mathrm{mg} \mathrm{kg} /$ body weight; Kemin Industries, Inc., Des Moines, Iowa/USA), canthaxanthin (0.2 mg kg/body weight; Hoffmann-La Roche, Grenzach-Wyhlen/ Germany) and $\alpha$-tocopherol (1.4 $\mathrm{mg} \mathrm{kg} /$ body weight; Hoffmann-La Roche, Grenzach-Wyhlen/Germany). $\beta$-carotene, canthaxanthin and $\alpha$-tocopherol were dispersed in $3 \mathrm{ml}$ of whipping cream. Lycopene and lutein were dissolved in $2 \mathrm{ml}$ olive oil. After using an ultrasonic bath for homogenization, both mixtures were combined in an edible cup and given to the volunteers.

As a dietary fiber supplement, pectin (galacturonic acid $>65 \%$, Copenhagen Pectin A/S, Denmark, X 5114, Batch No 5150485), guar (Welding GmbH \& Co, Hamburg, Germany), and cellulose (J. Rettenmaier and sons, Ellwangen-Holzmühle, Type L 600, Germany) were used. The special fiber was mixed with the rice pudding $(0.15$ $\mathrm{mg} / \mathrm{kg}$ body weight) ten minutes before serving. Table 
Table 1 Carotenoid and $\alpha$-tocopherol profile in plasma lipoproteins of six healthy women before supplementation (mean \pm SEM, $\mathrm{n}=6$ )

\begin{tabular}{|c|c|c|c|c|c|c|}
\hline & $\begin{array}{c}\text { VLDL } \\
\mu \mathrm{mol} / \mathrm{mmol} \\
\text { VLDL cholesterol }\end{array}$ & $\%{ }^{\#}$ & $\begin{array}{c}\text { LDL } \\
\mu \mathrm{mol} / \mathrm{mmol} \\
\text { LDL cholesterol }\end{array}$ & $\%$ & $\begin{array}{c}\text { HDL } \\
\mu \mathrm{mol} / \mathrm{mmol} \\
\text { HDL cholesterol }\end{array}$ & $\%^{\#}$ \\
\hline ß-carotene & $0.208 \pm 0.003$ & 25 & $0.385 \pm 0.060$ & 46 & $0.242 \pm 0.029$ & 29 \\
\hline lycopene & $0.031 \pm 0.031$ & 11 & $0.166 \pm 0.034$ & 58 & $0.085 \pm 0.023$ & 31 \\
\hline lutein & $0.109 \pm 0.012$ & 40 & $0.035 \pm 0.003$ & 12 & $0.134 \pm 0.013$ & 48 \\
\hline canthaxanthin & b.d. & & b.d. & & b.d. & \\
\hline$\alpha$-tocopherol & $7.962 \pm 0.342$ & 49 & $2.786 \pm 0.166$ & 17 & $5.514 \pm 0.512$ & 34 \\
\hline
\end{tabular}

b.d. below detection limit

\# $\%$ of the combined VLDL + LDL + HDL concentrations

Table 2 Carotenoid and $\alpha$-tocopherol concentrations [ $\mu \mathrm{mol} / \mathrm{mmol}$ LDL cholesterol] in LDL before $(0 \mathrm{~h})$ as well as 8,10 , and 24 hours after a single oral dose of a carotenoid and $\alpha$-tocopherol mixture without addition of dietary fiber to the test meal (mean $\pm \operatorname{SEM}, \mathrm{n}=6)$

\begin{tabular}{|c|c|c|c|c|c|c|c|}
\hline & $\begin{array}{c}0 \mathrm{~h} \\
\mu \mathrm{mol} / \mathrm{mmol} \\
\mathrm{LDL} \text { chol. }\end{array}$ & $\begin{array}{c}8 \mathrm{~h} \\
\mu \mathrm{mol} / \mathrm{mmol} \\
\text { LDL chol. }\end{array}$ & $\%{ }^{\#}$ & $\begin{array}{c}10 \mathrm{~h} \\
\mu \mathrm{mol} / \mathrm{mmol} \\
\mathrm{LDL} \text { chol. }\end{array}$ & $\%$ & $\begin{array}{c}24 \mathrm{~h} \\
\mu \mathrm{mol} / \mathrm{mmol} \\
\mathrm{LDL} \text { chol. }\end{array}$ & $\%{ }^{\#}$ \\
\hline ß-carotene & $0.398 \pm 0.051^{\mathrm{a}}$ & $0.468 \pm 0.063^{b}$ & 22 & $0.497 \pm 0.048^{\mathrm{b}, \mathrm{c}}$ & 29 & $0.542 \pm 0.042^{\mathrm{c}}$ & 41 \\
\hline lycopene & $0.166 \pm 0.034$ & $0.171 \pm 0.025$ & 7 & $0.173 \pm 0.032$ & 8 & $0.182 \pm 0.027$ & 14 \\
\hline lutein & $0.035 \pm 0.003$ & $0.040 \pm 0.004$ & 14 & $0.040 \pm 0.004$ & 14 & $0.040 \pm 0.005$ & 14 \\
\hline canthaxanthin & $0.000 \pm 0.000^{\mathrm{a}}$ & $0.046 \pm 0.006^{b}$ & $46^{\S}$ & $0.063 \pm 0.014^{\mathrm{b}}$ & $63^{\$}$ & $0.056 \pm 0.015^{\mathrm{b}}$ & $56^{\$}$ \\
\hline$\alpha$-tocopherol & $2.775 \pm 0.110^{\mathrm{a}}$ & $3.425 \pm 0.087^{b}$ & 23 & $3.449 \pm 0.107^{b}$ & 24 & $3.265 \pm 0.182^{b}$ & 17 \\
\hline$\sum$ antioxidants & $3.367 \pm 0.157^{\mathrm{a}}$ & $4.149 \pm 0.123^{b}$ & 23 & $4.221 \pm 0.082^{b}$ & 25 & $4.085 \pm 0.195^{\mathrm{b}}$ & 23 \\
\hline
\end{tabular}

a,b,c Means with no common letters differ significantly between time points, $\mathrm{p} \leq 0.05$, snk test

\# $\%$ of the 0 -h value

$\$$ absolute value multiplied by 100 , because 0 -h value is under detection limit

water was used to obtain comparable consistencies of the meals. The test meal was given to the subjects together with the antioxidant mixture.

Lipoprotein preparation and in vitro oxidation of LDL

Blood samples from the subjects were taken in tubes containing EDTA (1.6 mg/ml blood; Sigma, Deisenhofen/Germany). Lipoproteins were prepared immediately by stepwise ultracentrifugation with a $\mathrm{KBr}$ density gradient of 1,000-1,006 $\mathrm{g} / \mathrm{cm}^{3}$ for VLDL, 1,006-1,063 g/ $\mathrm{cm}^{3}$ for LDL and 1,063-1,210 g/ $\mathrm{cm}^{3}$ for HDL [25]. All saline solutions contained $380 \mathrm{mg}$ EDTA/l.

Cholesterol and triacylglycerol concentrations in plasma and lipoprotein fractions were measured by using commercially available enzymatic colorimetric assays (CHOD PAP and GPO PAP, Boehringer Mannheim, Germany).
For use in the in vitro oxidation assay, LDL samples were dialysed against phosphate-buffered saline before analysis in order to remove all EDTA. The freshly dialysed LDL samples were diluted with the phosphate buffer to a final concentration of $0.25 \mathrm{mg} \mathrm{LDL} / \mathrm{ml}$, using the cholesterol content of LDL for calculation. The LDL oxidation was started by addition of $10 \mu \mathrm{l}$ of $1.66 \mathrm{mM} \mathrm{CuCl}_{2}$ to one $\mathrm{ml}$ of the diluted LDL solution. The formation of conjugated dienes was measured over a period of two hours by monitoring the increase of the $234 \mathrm{~nm}$ absorbance against reagent blank at $37{ }^{\circ} \mathrm{C}$. The lag phase was determined graphically [26].

Antioxidant measurements

Concentrations of carotenoids and $\alpha$-tocopherol in isolated lipoprotein fractions were quantified by HPLC using a modified version of the method described by Hess et al. 
[27]. For analysis, 1-2 $\mathrm{ml}$ lipoprotein fraction was mixed with $2 \mathrm{ml}$ ethanol containing $\beta$-apo-8'-carotenoic acid ethyl-ester and tocopheryl acetate as internal standards. The mixture was extracted twice using hexane as solvent. The combined hexane layers were evaporated under vacuum, and redissolved in $200 \mu \mathrm{l}$ HPLC eluent. A sample $(20 \mu \mathrm{l})$ was injected into HPLC system installed with a reversed phase C-18 column (ultrasphere ODS, $4.5 \mathrm{~mm} \mathrm{x}$ $150 \mathrm{~mm}$, Beckman München/Germany; precolumn ultrasphere ODS, 4.5 mm x 45 mm, Beckman München, Germany). Analysis of carotenoids and $\alpha$-tocopherol was performed by detection at $450 \mathrm{~nm}$ and $292 \mathrm{~nm}$ absorbances, respectively, after elution with acetonitrile/dichlormethane/methanol $\left(7 / 2 / 1, \mathrm{v} / \mathrm{v} / \mathrm{v} ; 1.2 \mathrm{ml} / \mathrm{min}, 18^{\circ} \mathrm{C}\right)$ using an UV/VIS detector UVD340S (Gynkotek Germering, Germany). Calculations were made using the internal standard method and relative response factors. Recovery of the carotenoids and $\alpha$-tocopherol after enrichment of serum samples was within 94 and $107 \%$ with a coefficient of variation $<2.3 \%(n=5)$.

The vitamin $\mathrm{C}$ content of plasma samples was analyzed by photometry $(520 \mathrm{~nm})$ according to the method of Lowry et al. [28]. Ascorbic acid (Sigma, Deisenhofen, Germany) standard solution was taken for calibration. Mean recovery of ascorbic acid added to plasma samples $(n=7)$ was $101.6 \%$ with a coefficient of variation of $0.7 \%$.

Plasma selenium was determined by graphite furnance atomic absorption spectrometry, using a Perkin-Elmer 2380 atomic absorption spectrophotometer. Sample preparation and analysis conditions were adapted from Welz et al. [29] using $\mathrm{Pd}\left(\mathrm{NO}_{3}\right) \mathrm{H}_{2} \mathrm{O}$ and $\mathrm{Mg}\left(\mathrm{NO}_{3}\right) 2 \mathrm{H}_{2} \mathrm{O}$ as matrix modifiers. Quality control was made with Seronorm Trace Element Serum (Promochem, Wesel, Germany). Mean recovery of selenium (standard solution) added to plasma samples $(n=4)$ was $96.9 \%$ with a coefficient of variation of $6.7 \%$.

\section{AUC calculation}

The area under curve (AUC) method was used to quantify the carotenoid and $\alpha$-tocopherol enrichment in LDL over 24 hours.

\section{Statistics}

The results were given as mean and standard error of mean (SEM). All carotenoid and $\alpha$-tocopherol concentrations in lipoproteins were standardized on the cholesterol concentration of the same lipoprotein.

Statistical analysis was performed with SPSS, Vers. 7.5 for Windows 95 (SPSS Inc. Chicago, USA). The repeated measures model was used to test the effect of the time point on the change in LDL antioxidant and lag phase time, considering the dietary fiber treatment as a between subjects factor. After using a multifactorial model for analysis of variance (factors person, time after supplementation, dietary fiber), comparisons of group means were made with the Student-Newman-Keuls (snk) test at an $\alpha$-level of $5 \%$.

\section{Results}

In fasted state the majority of $\beta$-carotene and lycopene was located in LDL ( $46 \%$ and $58 \%$, respectively), while lutein and $\alpha$-tocopherol were mainly located in VLDL and HDL (standardized based on cholesterol, Table 1). The single oral supplementation of the mixture of four carotenoids and $\alpha$-tocopherol increased the concentrations of the supplemented compounds in all lipoprotein fractions (data shown for LDL, Table 2). However, the distribution of carotenoids and $\alpha$-tocopherol between lipoproteins was not altered by the antioxidant supplementation.

Table 3 Area under the curve $(0-24 \mathrm{~h})$ of carotenoid and $\alpha$-tocopherol concentrations in LDL [ $\mu \mathrm{mol} * \mathrm{~h} *$ mmol LDL cholesterol-1 $]$ after a single oral dose of a carotenoid and $\alpha$-tocopherol mixture without and with addition of different kinds of dietary fiber to the test meal $($ mean \pm SEM, $n=6$ )

\begin{tabular}{lrrrrrrrr}
\hline & without fiber & $\%$ & pectin & \%\# & guar & \% $^{\#}$ & cellulose & \% $^{\#}$ \\
\hline B-carotene & $2.28 \pm 0.49$ & 100 & $0.85 \pm 0.28$ & 37 & $2.07 \pm 0.87$ & 91 & $1.96 \pm 0.38$ & 86 \\
lycopene & $0.29 \pm 0.13$ & 100 & $0.29 \pm 0.09$ & 100 & $0.26 \pm 0.09$ & 90 & $0.09 \pm 0.22$ & 31 \\
lutein & $0.11 \pm 0.03$ & 100 & $0.09 \pm 0.03$ & 82 & $0.03 \pm 0.03$ & 27 & $0.02 \pm 0.04$ & 18 \\
canthaxanthin & $1.12 \pm 0.21$ & 100 & $0.91 \pm 0.14$ & 81 & $0.82 \pm 0.05$ & 73 & $0.88 \pm 0.06$ & 79 \\
$\alpha$-tocopherol & $12.58 \pm 2.15$ & 100 & $12.56 \pm 2.09$ & 100 & $9.63 \pm 2.81$ & 77 & $11.16 \pm 3.17$ & 89 \\
$\sum$ antioxidants & $16.11 \pm 2.72$ & 100 & $15.54 \pm 2.77$ & 97 & $12.43 \pm 3.09$ & 77 & $14.07 \pm 3.68$ & 87 \\
\hline
\end{tabular}

\# $\%$ of the area in the trial without addition of dietary fiber to the test meal

Analysis of variance showed no statistically significant effect of dietary fiber supplementation 
Fig. 1 Relative change [\% of $0 \mathrm{~h}$ value] of the sum of the carotenoid and $\alpha$-tocopherol concentrations in LDL 8, 10, and 24 hours after a single oral dose of a carotenoid and $\alpha$-tocopherol mixture without and with the addition of different kinds of dietary fiber to the test meal.

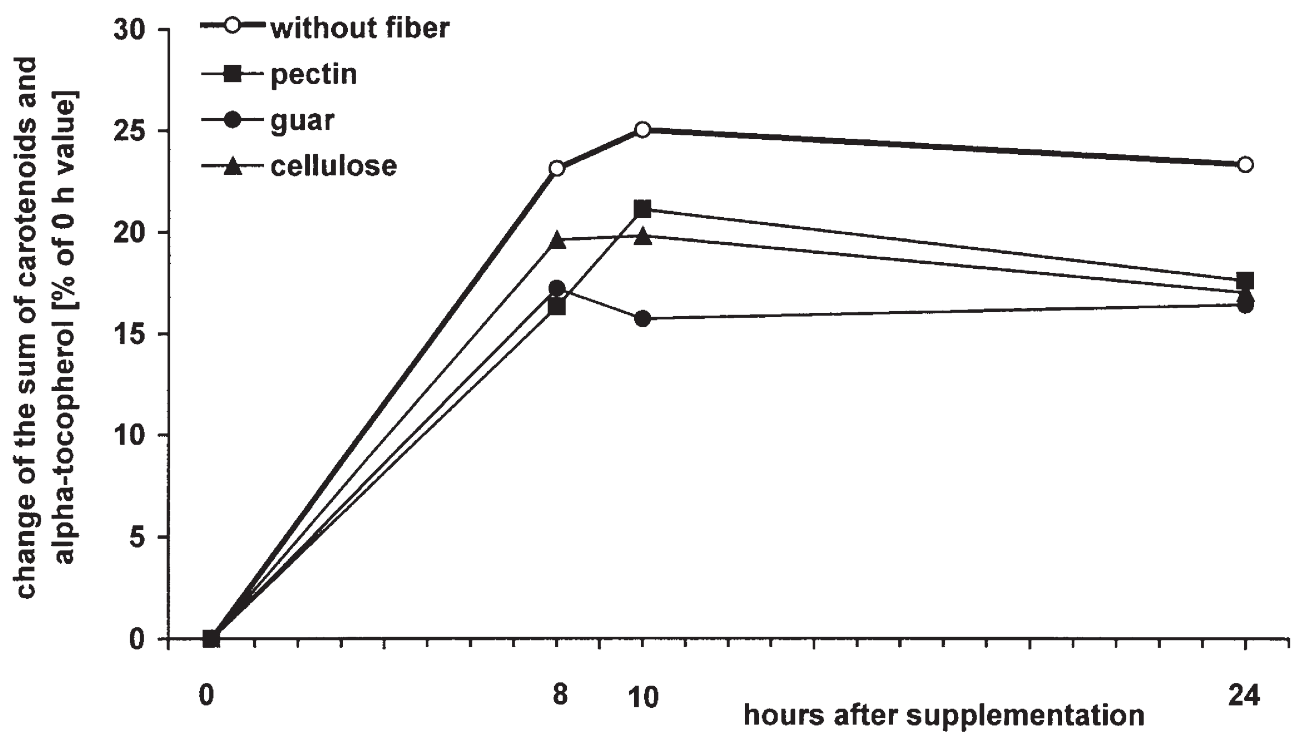

Canthaxanthin was not found in the lipoproteins before supplementation. Twenty-four hours after supplementation, $56 \%$ of canthaxanthin was found in VLDL, $26 \%$ in LDL, and $18 \%$ in HDL. Maximum enrichment of LDL was reached after 8 hours (lutein), 10 hours (canthaxantin, $\alpha$-tocopherol) and 24 hours (lycopene, $\beta$-carotene). The results of pre-studies with two subjects revealed no higher enrichment after 24 hours for $\beta$-carotene and lycopene.

The addition of pectin, guar, or cellulose to the test meal diminished the increase of the carotenoid and $\alpha$-tocopherol concentrations in LDL. This is shown by the calculated values of the AUC over 24 hours for the different carotenoids and $\alpha$-tocopherol (Table 3), as well as by the relative change of the sum of the carotenoids and $\alpha$-tocopherol ( $\%$ of 0 -h value; Fig. 1). However, the effect of dietary fiber differed among the supplemented an- tioxidants. The mean AUC of LDL $\beta$-carotene was mostly influenced by pectin, while cellulose revealed the strongest effect on LDL lutein and lycopene; LDL $\alpha$-tocopherol was mostly affected by guar. The mean AUC of LDL canthaxanthin was diminished by all types of fiber to a similar extent. The observed effects of dietary fiber supplementation were not of statistical significance.

A significantly longer lag phase in LDL was observed after antioxidant supplementation without addition of dietary fiber, as a result of the higher carotenoid and $\alpha$-tocopherol concentrations in LDL (Table 4). The addition of pectin, guar, or cellulose to the test meal reduced the prolongation of the lag phase in comparison to the test run without fiber.

Because of the antioxidative function of ascorbic acid and selenium as constituents of glutathion peroxidase, their plasma concentrations were controlled. The concen-

Table 4 Lag phase of LDL before $(0 \mathrm{~h})$ as well as 8, 10, and 24 hours after a single oral dose of a carotenoid and $\alpha$-tocopherol mixture without and with the addition of different kinds of dietary fiber to the test meal (mean \pm SEM, $n=6$ )

\begin{tabular}{|c|c|c|c|c|c|c|c|c|}
\hline \multicolumn{9}{|c|}{ lag phase [min] } \\
\hline & $0 \mathrm{~h}$ & $\%$ & $8 \mathrm{~h}$ & $\%$ & $10 \mathrm{~h}$ & $\% \#$ & $24 \mathrm{~h}$ & $\%{ }^{\#}$ \\
\hline without fiber & $26.0 \pm 2.6^{\mathrm{a}}$ & 100 & $32.3 \pm 2.0^{\mathrm{b}}$ & 124 & $31.3 \pm 3.9^{\mathrm{a}, \mathrm{b}}$ & 120 & $30.1 \pm 3.6^{\mathrm{a}, \mathrm{b}}$ & 116 \\
\hline Pectin & $45.5 \pm 8.4$ & 100 & $47.3 \pm 8.2$ & 104 & $48.4 \pm 8.6$ & 106 & $52.0 \pm 9.0$ & 114 \\
\hline Guar & $38.7 \pm 4.0^{\mathrm{a}}$ & 100 & $44.5 \pm 5.1^{b}$ & 115 & $41.3 \pm 3.5^{\mathrm{a}, \mathrm{b}}$ & 107 & $44.7 \pm 4.2^{b}$ & 116 \\
\hline Cellulose & $45.3 \pm 8.1$ & 100 & $53.4 \pm 14.8$ & 118 & $50.8 \pm 8.5$ & 112 & $48.5 \pm 9.0$ & 107 \\
\hline
\end{tabular}

\# $\%$ of the 0 -h value within dietary fiber group

a,b means with no common letters differ significantly between time points, $\mathrm{p} \leq 0.05$, snk test

Using the repeated measures model a statistically significant effect of the time after supplementation but not of the dietary fiber addition was found 
Table 5 Cholesterol and triacylglycerol concentrations [mmol/1] in LDL before $(0 \mathrm{~h})$ as well as 8,10 , and 24 hours after a single oral dose of a carotenoid and $\alpha$-tocopherol mixture without and with the addition of different kinds of dietary fiber to the test meal (mean \pm SEM, $\mathrm{n}=6$ )

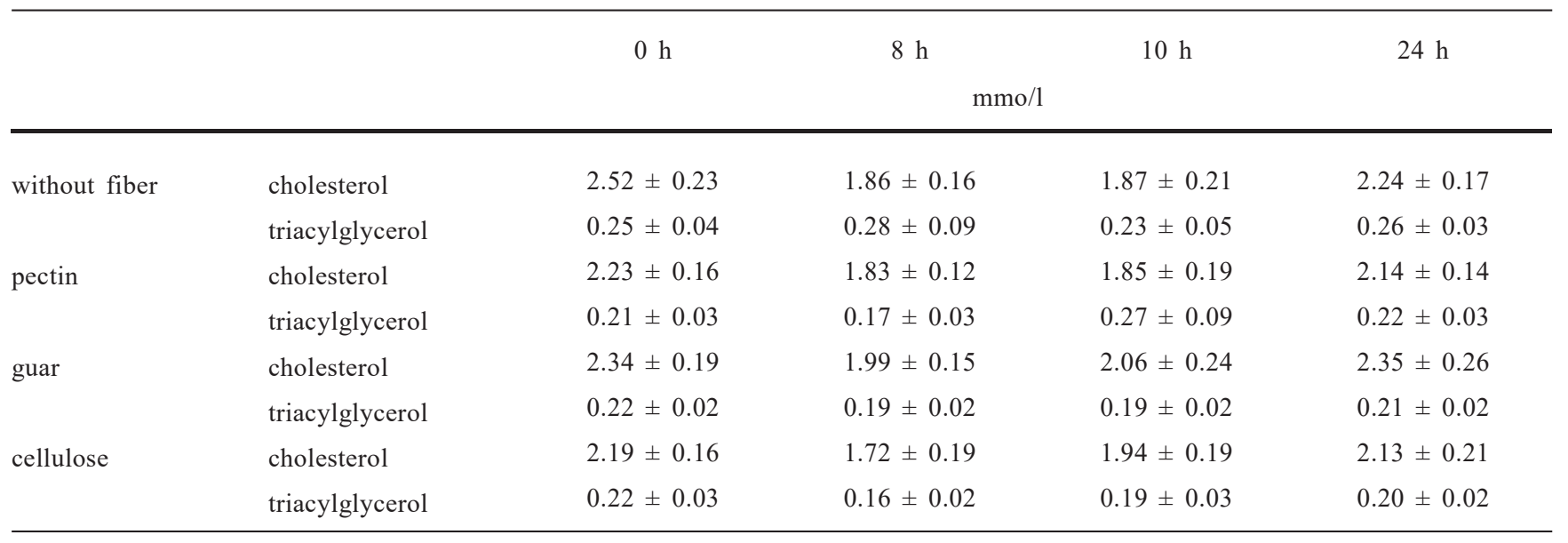

Analysis of variance showed no statistically significant effect of the time after supplementation and the dietary fiber addition

trations were almost constant and are between $85.9 \mu \mathrm{mol} / 1$ and $125.3 \mu \mathrm{mol} / 1$ for ascorbic acid, and $0.5 \mu \mathrm{mol} / 1$ and 0.8 $\mu \mathrm{mol} / \mathrm{l}$ for selenium (data not shown).

Analysis of variance showed that the cholesterol and triacylglycerol concentrations in lipoproteins were not significantly affected by this short-term antioxidant and dietary fiber supplementation (Table 5).

\section{Discussion}

Carotenoids and $\alpha$-tocopherol are transported in the plasma of humans exclusively by lipoproteins. Their relative distribution differs among the lipoprotein fractions VLDL, LDL and HDL, and is thought to be a function of their polarity [30, 31]. Unpolar hydrocarbon carotenoids like $\beta$-carotene and lycopene associate predominantly with LDL, while the more polar dihydroxy-carotenoid lutein, as well as $\alpha$-tocopherol, associate less with LDL and more with HDL [32]. In this study antioxidant concentrations were standardized based on cholesterol levels of lipoproteins. Accordingly, concentrations in LDL appear lower because of the high cholesterol content in LDL. Administration of the antioxidant mixture as well as the addition of dietary fiber to the test meal affect the antioxidant concentrations in the lipoprotein fractions, but the relative distribution among the lipoproteins was unchanged. Thus, a prefered enrichment of one lipoprotein class after supplementation could not be observed.

The varying polarity of carotenoids and $\alpha$-tocopherol, which determines their location in lipoproteins, also determines their location in the LDL particle. Nonpolar carotenoids like $\beta$-carotene and lycopene are located exclu- sively in the hydrophobic core of the particle, whereas carotenoids with polar functional groups (lutein, canthaxanthin) and above all $\alpha$-tocopherol exist, at least partially, at the surface [30]. The different locations of the various antioxidants in LDL lead to the assumption of synergistic effects as already shown for $\alpha$-tocopherol and ascorbic acid [17]. In addition, in LDL incubated with both lycopene and $\alpha$-tocopherol, the oxidative resistence increased far more than compared to incubation with single substances [33]. Therefore, in the present study a mixture of different antioxidants was administered to reach maximal effects on the oxidative susceptability of LDL. Indeed, it could be demonstrated that a single oral dose of a carotenoid and $\alpha$-tocopherol mixture enhanced the protection of LDL against copper-induced oxidation in terms of lag phase prolongation and the formation of cholesterol oxidation products [34]. Effects of carotenoid interactions on bioavailability of carotenoids, when given simultaneously, were evident in several studies, but the results are inconsistent [19-21]. In the present study the absorption interactions of carotenoids and $\alpha$-tocopherol were kept constant throughout the experiment by administration of an identical supplement composition in all test runs.

Based on the results of several studies, it is generally accepted that $\alpha$-tocopherol can inhibit LDL oxidation [5, 6 , 8, 35-37]. Regarding $\beta$-carotene, Levy et al. [13] showed that a high single dose of $\beta$-carotene $(300 \mathrm{mg})$ reduced the oxidative modification of LDL as measured by thiobarbituric acid-reactive substances generated after lipid peroxidation in the presence of copper ions. However, the function of $\beta$-carotene in protecting LDL from oxidation is controversially discussed. Several investigations showed that $\beta$-carotene supplementation does not enhance resistance of LDL $[12,14,15]$. Possibly, an anti- 
oxidative effect of $\beta$-carotene was not observed because of very high $\alpha$-tocopherol supplements in some studies [33]. Gaziano et al. [12] supplemented 50-100 mg $\beta$-carotene for three weeks without any $\alpha$-tocopherol administration, but in spite of a 8.5 -fold increase in LDL- $\beta$-carotene concentrations, no prolongation of lag phase could be measured. Lutein and canthaxanthin are also effective as antioxidants in vitro [10], but oral supplementation with lutein $(30 \mathrm{mg} /$ day) for two weeks showed no effect on the prolongation of lag phase after copper ion-induced oxidation, although there was a sixfold increase in lutein concentration in LDL [38]. Comparable to $\beta$-carotene and lycopene, an antioxidative effect of lutein is possible only in combination with other antioxidants, like carotenoids or $\alpha$-tocopherol. In the present study, 24 hours after supplementation the $\alpha$-tocopherol concentration in LDL and the lag phase of LDL concomitantly decreased, while $\beta$-carotene and lycopene concentrations in LDL still increased. This confirms the results of several other studies $[18,33,39]$, which had shown that with simultaneous supplementation of carotenoids and $\alpha$-tocopherol, $\alpha$-tocopherol had the strongest effect on LDL lag phase prolongation.

To investigate the effect of the addition of different kinds of dietary fiber to the test meal, the area under the curve over 24 hours was calculated. By means of the $\mathrm{AUC}_{24 \mathrm{~h}}$ value the change in LDL concentrations of the antioxidants in the different dietary fiber supplementation groups can be easily compared. This method was also used to describe the lag phase from 0-24 hours, allowing an immediate comparison of the effects of the dietary fibers. The present results show that the protective effect of a carotenoid and $\alpha$-tocopherol mixture on the oxidative resistance of LDL is reduced by the addition of each kind of dietary fiber administered. The strongest effect was seen with addition of pectin ( $38 \%$ reduction), followed by guar $(22 \%)$ and cellulose $(18 \%)$. These effects are the result of a reduced antioxidant enrichment of LDL by the action of dietary fibers at the absorption site. Riedl et al. [40] showed that dietary fiber decreases the relative absorption of carotenoids and $\alpha$-tocopherol. The bioavailability of lycopene and lutein was significantly reduced by pectin, guar, and cellulose, whereas the absorption of $\beta$-carotene was significantly lowered only by pectin and guar. The effect of dietary fiber on the bioavailability of canthaxanthin and $\alpha$-tocopherol was smaller and statisti- cally not significant. In the present study the extent of the reduction of the LDL antioxidant concentrations also varied between the substances. However, the sum of the antioxidant concentrations matches the reduction of the lag phase values by dietary fiber. Especially after addition of pectin only a small increase of the lag phase was observed 8 and 10 hours thereafter (Table 4). This may possibly be the consequence of the relatively small increase of $\beta$-carotene concentration in LDL 8 and 10 hours after pectin ingestion; all other supplemented antioxidants were found to result in higher LDL concentrations with pectin when compared to guar or cellulose addition. Therefore, an important role of $\beta$-carotene for the oxidative protection of LDL is still conceivable.

The effect of dietary pectin on $\beta$-carotene response after supplementation is known from earlier work. Studies with chicks [41] and humans [23] suggested that the addition of pectin to chow or test meal reduced the bioavailability of $\beta$-carotene. Riedl et al. [40] also showed that pectin decreased the bioavailability of $\beta$-carotene by $42 \%$. The mode of action of carotenoids and specific components of dietary fiber is not clear. It is possible that micelle formation, necessary for the absorption of lipophilic substances, is disturbed by viscous polysaccharides [23]. Furthermore, dietary fiber increases the viscosity of the intestinal content. This results in a reduced absorption of macro- and micronutrients because of the slow down of the activity of pancreatic enzymes and more difficult contact with intestinal enterocytes $[42,43]$. In the present study, rather high carotenoid doses together with realistic fiber doses were administrated to the subjects. It can be hypothesized that the observed effect of dietary fiber may be different with "physiological" doses of carotenoids while the direction of possible changes remains open. This topic has to be stressed in further investigations.

In conclusion, the results of the study demonstrates that the intake of a mixture of carotenoids and $\alpha$-tocopherol significantly increased their LDL concentrations as well as the LDL oxidation resistance. A concomitant addition of dietary fiber to the test meal produced a nonsignificant decrease in carotenoid and $\alpha$-tocopherol enrichment of LDL together with a lower resistance of these LDL to oxidation. With the use of a more sensitive methodology (e.g., labeling of carotenoids with stable isotopes), the present results could be evaluated for the administration of "physiological" doses of carotenoids.

\section{References}

1. Halliwell B (1995) Oxidation of low density lipoproteins: question of initiation, propagation, and the effect of antioxidants. Am J Clin Nutr 61 (suppl): 670S-677S

2. Steinberg D, Parthasarathy S, Carew T, Khoo JC, Witztum JL (1989) Beyond cholesterol. Modifications of LDL that increase its atherogenicity. N Engl J Med: 915-924

3. Jessup A, Rankin CM, De Whally CV, Hoult JRS, Scott J, Leake DS (1990) $\alpha$-tocopherol consumption during lowdensity-lipoprotein oxidation. Biochem J 265:399-405
4. Esterbauer H, Gebicki J, Puhl H, Jürgens G (1992) The role of lipid peroxidation and antioxidants in oxidative modification of LDL. Free Rad Biol \& Med 13:341-350

5. Princen H.M.G, v. Düyvenvoorde W, Buytenhek $R$, van der Laarse $A$, van Poppel G, Leuven JAG, van Hinsbergh 
VWM (1995) Supplementation with low doses of vitamin E protects LDL from lipid peroxidation in men and women. Arterioscler Thromb Vasc Biol 15: $325-333$

6. Jialal I, Fuller CJ, Huet BA (1995) The effect of $\alpha$-tocopherol supplementation on LDL oxidation. A dose-response study. Arterioscler Thromb Vasc Biol 15: $190-198$

7. Porkkala-Sarataho E, Nyyssönen K, Salonen JT (1996) Increased oxidation resistance of atherogenic plasma lipoproteins at high vitamin $\mathrm{E}$ levels in non-vitamin E supplemented men. Atherosclerosis 124: 83-94

8. Dieber-Rotheneder M, Puhl H, Waeg G, Striegl G, Esterbauer H (1991) Effect of oral supplementation with d- $\alpha$-tocopherol on the vitamin E content of human low density lipoproteins and resistance to oxidation. J Lipid Res 32: $1325-1332$

9. Lavy A, Amotz AB, Aviram M (1993) Preferential inhibition of LDL oxidation by the alltrans isomer of $\beta$-carotene in comparison with 9-cis- $\beta$-carotene. Europ J Clin Chem Clin Biochem 31: 83-90

10. McLoone UJ, Chopra M, Williams NR, Thurnham DI (1995) The effect of in vitro and in vivo supplementation with lutein on LDL oxidation in vitro. Proc Nutr Soc 54: 168A

11. DiMascio P, Sundquist AR, Devasagayam TPA, Sies H (1992) Assay of lycopene and other carotenoids as singlet oxygen quenchers. Method Enzym 213: 429-438

12. Gaziano JM, Hatta A, Flynn M, Johnson EJ, Krinsky NI, Ridker PM, Hennekens CH, Frei B (1995) Supplementation with $\beta$-carotene in vivo and in vitro does not inhibit low density lipoprotein oxidation. Atherosclerosis 112: 187-195

13. Levy Y, Ben-Amotz A, Aviram M (1995) Effect of diatary supplementation of different $\beta$-carotene isomers on lipoprotein oxidative modification. Journal of Nutritional \& Environmental Medicine 5: 13-22

14. Reaven PD, Khouw A, Beltz WF, Parthasarathy S, Witztum JL (1993) Effect of dietary antioxidant combinations in humans. Protection of LDL by vitamin E but not by $\beta$-carotene. Arteriosclerosis and Thrombosis 13: 590-600

15. Jialal I, Grundy SM (1993) Effect of combined supplementation with $\alpha$-tocopherol, ascorbate, and $\beta$-carotene on low density lipoprotein oxidation. Circulation 88: 2780-2786

16. Thomas SR, Neuzil J, Mohr D, Stocker $\mathrm{R}$ (1995) Coantioxidants make $\alpha$-tocopherol an efficient antioxidant for low-density lipoprotein. Am J Clin Nutr 62 (suppl.): 1357S-1364S

17. Niki E, Noguchi N, Tsuchihashi $H$, Gotoh N (1995) Interaction among vi- tamin $C$, vitamin $E$, and $\beta$-carotene. Am J Clin Nutr 62: 1322S-1326S

18. Pallozza P, Krinsky MI (1992) Betacarotene and alpha-tocopherol are synergistic antioxidants. Arch Biochem Biophys 297: S184-S187

19. Johnson EJ, Qin J, Krinsky NI, Russell RM (1997) Ingestion by men of a combined dose of $\beta$-carotene and lycopene does not affect the absorption of $\beta$ carotene but improves that of lycopene. J Nutr 127: 1833-1837

20. Pateau I, Chew H, Goh NMY, White WS (1997) Interactions in the postprandial appearance of $\beta$-carotene and canthaxanthin in plasma triacylglycerolrich lipoproteins in humans. Am J Clin Nutr 66: 1133-1143

21. Kostic D, White WS, Olson JA (1995) Intestinal absorption, serum clearance, and interactions between lutein, and $\beta$-carotene when administered to human adults in separate or combined oral doses. Am J Clin Nutr 62 604-610

22. Tang G, Dolnikowski GG, Blanco MC Fox JG, Russell RM (1993) Serum carotenoids and retinoids in ferrets fec cathaxanthin. J Nutr Biochem 4: 58-63

23. Rock CL, Swendseid ME (1992) Plasma $\beta$-carotene response in humans after meals supplemented with dietary pectin. Am J Clin Nutr 55: 96-99

24. National Research Council. Subcommitee on the Tenth Edition of RADS (1989) Recommended dietary allowances. National Academic Press, Washington

25. Havel RJ, Eder HA, Bragdon JH (1955) The distribution and chemical composition of ultracentrifugally separated lipoproteins in human serum. J Clin Invest 34: 1345-1353

26. Esterbauer H, Striegl G, Puhl H, Rotheneder M (1989) Continous monitoring of in vitro oxidation of human low density lipoprotein. Free Rad Res Comms 6: 67-75

27. Hess D, Keller HE, Oberlin B, Bonfanti R, Schuep W (1990) Simultanous determination of retinol, tocopherols, carotenes, and lycopene in plasma by means of high-performance liquid chromatography on reversed phase. Internat J Vit Nutr Res 61: 232-238

28. Lowry OH, Lopez JA, Bessey OA (1943) The determination of ascorbic acid in small amounts of serum. J Biol Chem 147: 609-615

29. Welz B, Schlemmer G, Mudakavi JR (1988) Palladium nitrate - magnesium nitrate modifier for graphite furnace atomic absorption spectrometry. Part 1 : Determination of arsenic, antimony, selenium and thallium in airborne particulate matter. J Anal Atomic Spec 3: 93-97

30. Parker RS (1996) Absorption, metabolism, transport of carotenoids. FASEB J 10:542-551
31. Edmond LM, McLoone UJ, Thurnham DI, Chopra M (1995) The localisation of a carotenoid in a lipoprotein is a function of its polarity. Proc Nutr Soc 54: $167 \mathrm{~A}$

32. Clevidence BA, Bieri JG (1993) Associations of carotenoids with human plasma lipoproteins. Methods Enzymol 214: 33-46

33. Fuhrman B, Ben-Yaish L, Hayek T, Aviram M (1997) Tomato lycopene and $\beta$-carotene inhibit low density lipoprotein oxidation and this effect depends on the lipoprotein vitamin E content. Nutr Metab Cardiovasc Dis 7: 433-443

34. Linseisen J, Hoffmann J, Riedl J, Wolfram G (1998) Effect of a single ora dose of antioxidant mixture (vitamin E, carotenoids) on the formation of cholesterol oxidation products after ex vivo LDL oxidation in humans. Eur $\mathrm{J}$ Med Res 3: 5-12

35. Waart de FG, Moser U, Kok FJ (1997) Vitamin E supplementation in elderly lowers the oxidation rate of linoleic in LDL. Atherosclerosis 133: 255-263

36. Suzukawa M, Ishikawa T, Yoshida H, Nakamura H (1995) Effect of in-vitro supplementation with low-dose vitamin E on susceptibility of low-density lipoprotein and high-density lipoprotein to oxidative modification. J Am Coll Nutr 14: 46-52

37. Abbey M, Nestel PJ, Baghurst PA (1993) Antioxidant vitamins and lowdensity-lipoprotein oxidation. Am J Clin Nutr 58: 525-532

38. Chopra M, McLoone U, O’Neill M, Williams N, Thurnham DI (1996) Fruit and vegetable supplementation - effect of ex vivo LDL oxidation in humans In: Kumpulainen JT, Salonen JT (eds) Natural Antioxidants and Cancer Prevention. The Royal Society of Chemistry, Cambridge, pp 150-155

39. Handelman GJ, van Kuijk FJGM, Chattergee A, Krinsky NI (1991) Characterisation of products formed during the autoxidation of beta-carotene. Free Radical Biol Med 10: 427-437

40. Riedl J, Linseisen J, Hoffmann J, Wolfram G (1999) Some dietary fiber reduce the absorption of carotenoids in women. J Nutr 129 (12):2170-6

41. Erdman JW, Bierer TL, Gugger ET (1991) Absorption and transport of carotenoids. Ann NY Acad Sci 669: 76-85

42. Schneeman BO (1990) Macronutrient absorption. In: Kritchevsky D, Bobfield C, Anderson JW (eds) Dietary Fiber. Chemistry, Physiology, and Health Effects. Plenum Press, New York, pp 157-166

43. Phillips DR (1986) The effect of guar gum in solution on diffusion of cholesterol mixed micelles. J Sci Food Agr 37: $548-552$ 